\title{
Analysis of Facial Asymmetry in Deformational Plagiocephaly Using Three-Dimensional Computed Tomographic Review
}

Il Yung Moon,

So Young Lim,

Kap Sung Oh

Department of Plastic Surgery,

Samsung Medical Center,

Sungkyunkwan University School of Medicine,

Seoul, Korea
No potential conflict of interest relevant to this article was reported.

\begin{abstract}
Background: Infants with deformational plagiocephaly (DP) usually present with cranial vault deformities as well as facial asymmetry. The purpose of this study was to use threedimensional anthropometric data to evaluate the influence of cranial deformities on facial asymmetry.

Methods: We analyzed three-dimensional computed tomography data for infants with DP $(n=48)$ and without DP ( $n=30$, control). Using 16 landmarks and 3 reference planes, 22 distance parameters and 2 angular parameters were compared. This cephalometric assessment focused on asymmetry of the orbits, nose, ears, maxilla, and mandible. We then assessed the correlation between 23 of the measurements and cranial vault asymmetry (CVA) for statistical significance using relative differences and correlation analysis.

Results: With the exception of few orbital asymmetry variables, most measurements indicated that the facial asymmetry was greater in infants with DP. Mandibular and nasal asymmetry was correlated highly with severity of CVA. Shortening of the ipsilateral mandibular body was particularly significant. There was no significant deformity in the maxilla or ear.

Conclusion: This study demonstrated that the cranial vault deformity in DP is associated with facial asymmetry. Compared with the control group, the infants with DP were found to have prominent asymmetry of the nose and mandible.
\end{abstract}

Keywords: Deformational plagiocephaly / Facial asymmetry / Three-dimensional computed tomography

\section{INTRODUCTION}

Plagiocephaly refers to an asymmetric shape of the cranium and can be caused either by craniosynostosis or by deformational forces. True synostoticplagiocephaly must be differentiated from deformational plagiocephaly (DP) because fusion of the cranial suture often results in increased intracranial pressure. Deformational or posi-

Correspondence: So Young Lim

Departments of Plastic and Reconstructive Surgery, Samsung Medical Center, Sungkyunkwan University School of Medicine, 81 Irwon-ro, Gangnam-gu, Seoul 135-710, Korea

E-mail: pslisy@naver.com

Received August 8, 2014 / Revised November 5, 2014 / Accepted December 5, 2014 tional plagiocephaly is not associated with increased intracranial pressure, and children with DP generally do not require surgical treatment. Usually, conservative management alone is sufficient.

DP is the most common cause of head deformity in infants [1] and results from uterine constraint and progresses under persistent mechanical force [2]. Its incidence has increased since the introduction of "back to sleep campaign" by the American Academy of Pediatrics in 1992, which has led to a remarkable reduction in the incidence of sudden infant death syndrome from 1.2/1,000 live births to 0.56/1,000 in 2001 [3,4]. However, the campaign has also increased the amount of time that newborns spend in supine position and, consequently, the incidence of DP. 
Various sources of sustained mechanical forces may distort the head and anterior craniofacial skeleton of an infant. This is characterized by ipsilateral occipital flatness, forehead bossing, zygomatic protrusion, anterior displacement of the auricle, and contralateral front-orbital zygomatic retrusion. Other etiologies include torticollis and myoneural dysfunction.

Previous studies have evaluated head deformities in patients with plagiocephaly. However, these reports have focused on head shape alone and have not included a control group. The purpose of this present case-control review is to evaluate the influence of positional head deformation on facial asymmetry using three-dimensional computed tomography (3D CT) skeletal analysis.

\section{METHODS}

After acquiring institutional review board approval, we retrospectively reviewed medical records and CT scans of infants with plagiocephaly as well as a control group of infants who underwent 3D CT scan imaging for indications other than plagiocephaly. The study population consisted of all patients who presented to our plastic surgery clinic from January 2010 through February 2012 for helmet treatment of DP. Medical records and pre-treatment CT data were used to confirm DP and to obtain anthropometric data.

Subjects in the plagiocephaly group met the following inclusion criteria: 1) Less than 24 months of age. 2) No congenital or medical problems except DP (diagonal difference $\geq 5 \mathrm{~mm}$ ). 3) No orthotic helmet therapy or surgical treatment prior to CT scans.

Subjects in the control group met the following inclusion criteria: 1) Less than 24 months of age. 2) No congenital or medical problems, including DP (diagonal difference $<5 \mathrm{~mm}$ ). 3) Underwent 3D CT to rule out facial fracture but no abnormal findings were present.

The 24-month cut-off was chosen because approximately $90 \%$ of postnatal skull growth occurs during the first 24 months of life $[5,6]$.

The CT scans were performed with a 64-slice multi-detectorrow computed tomography scanner (GE Healthcare, Waukesha, WI, USA) at either 1 or $2.5-\mathrm{mm}$ image slices, from vertex to mandible. The scanned data were obtained as Digital Imaging and Communication in Medicine (DICOM) files. 3D CT reconstruction images were produced using the Aquarius Intuition Unlimited program (Terarecon, Foster City, CA, USA).

Upon manual identification of osseous landmarks, reference planes were determined to evaluate facial skeleton symmetry (Fig. 1). The planes were based on midline structures of the skull base, which are unaffected by deformational force $[7,8]$.

Using 16 osseous landmarks and 3 reference planes, each child was measured for 22 distance and 2 angular parameters (Table 1) on both sides of the face. The relative differences in these measurements (Table 2) were use to determine the degree of asymmetry in the orbits, nose, ears, maxilla, and mandible:
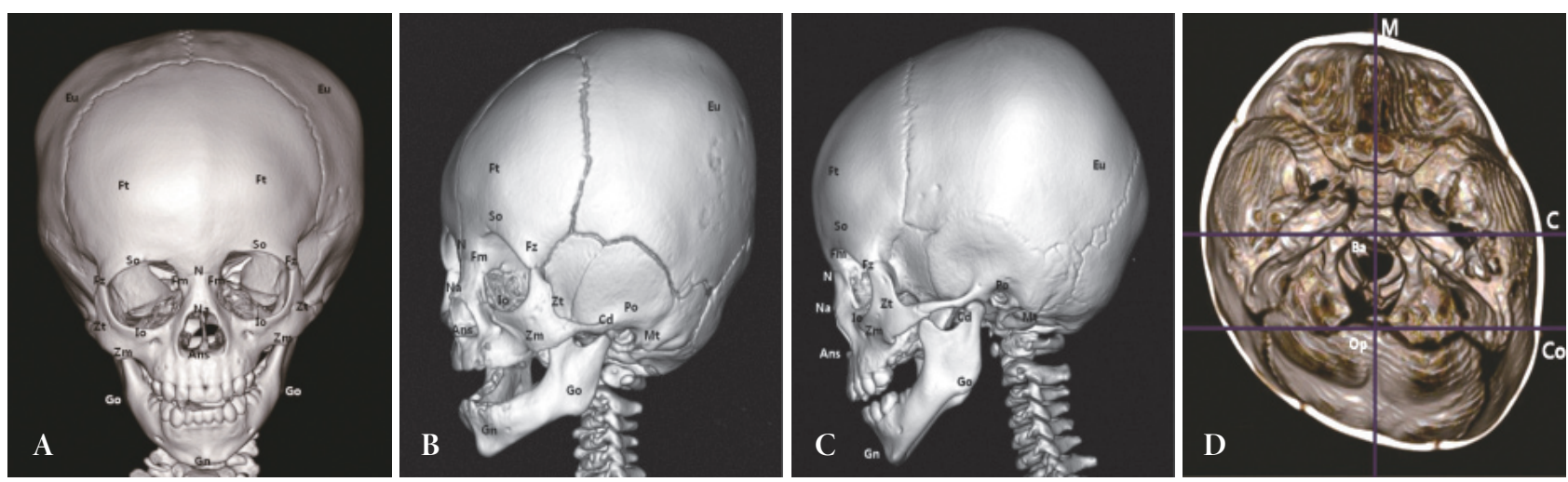

Fig. 1. Three-dimensional (3D) osseous landmark positions and reference planes on 3D computed tomography images of patients with left posterior deformational plagiocephaly. (A) anterior view, (B) oblique view, (C) lateral view, and (D) skull floor view. Ft, frontal bossing; Eu, eurion; Fz, frontozygomatic suture; Po, porion; N, nasion; Fm, frontomaxillary suture; So, superior orbitale; Io, inferior orbitale; C, coronal basion plane; Mt, mastoid tip; Ans, anterior nasal spine; $\mathrm{Na}$, nasale; $\mathrm{M}$, midsagittal plane; $\mathrm{Co}$, coronal opisthion plane; Zm, zygomaticomaxillary suture; Zt, zygotemporale; Gn, gnathion; Go, gonion; Cd, condylar process. 
relative difference $(\mathrm{RD})=100$ (ipsilateral measurement-contralateral measurement)/[(ipsilateral measurement+contralateral measurement) $/ 2](\%)$

Ipsilateral was defined as the side of occipital flatness. In some variables, in which the value of the ipsilateral measurement was smaller than that of the contralateral measurement, the RD value was a negative number (Table 2). However, the absolute value of the $\mathrm{RD}$ was used for asymmetry analysis between the plagiocephaly and control groups (Table 3) because there was no ipsilateral or contralateral side in the control group. All measurements were performed by the first author (I.Y.M.).

The measurements were tabulated, and analyses were performed using relative differences and correlation analyses. A Pearson correlation was used to evaluate any relationship between facial asymmetry and severity of cranial vault deformation (Table 4). Student's t-tests were used to compare facial asymmetry between the plagiocephaly and control groups (Table 3). A p-values $<0.05$ were consid- ered statistically significant. All statistical analyses were performed with the Statistical Package for the Social Sciences ver. 20.0 (IBM Co., Armonk, NY, USA).

\section{RESULTS}

Seventy-eight infants met the inclusion criteria for this study. We reviewed 48 infants with posterior DP and 30 infants without any craniofacial deformities. All of the patients in the control group had undergone computed tomography for trauma survey without any pertinent findings that would preclude anthropometric measurements.

The DP group included 17 girls and 31 boys. Right posterior plagiocephaly was present in 33 infants and left posterior plagiocephaly in 15 . The mean age at pretreatment CT scan was $8.5( \pm$ 4.4) months. Of the $48 \mathrm{DP}$ infants, 9 had torticollis (18.8\%). The control group included 12 girls and 18 boys. The mean age at CT

Table 1. Description of anthropometric osseous landmarks and reference planes

\begin{tabular}{|c|c|c|}
\hline Landmark and reference planes & Abbreviation & Definition \\
\hline Frontal bossing & $\mathrm{Ft}$ & The most prominent lateral point of the frontal bone \\
\hline Eurion & Eu & $\begin{array}{l}\text { The most prominent lateral point on each side of the parietal and } \\
\text { temporal bones }\end{array}$ \\
\hline Frontozygomatic suture & $\mathrm{Fz}$ & The medial point of the frontozygomatic suture \\
\hline Frontomaxillary suture & $\mathrm{Fm}$ & The lateral point of the frontomaxillary suture \\
\hline Superior orbitale & So & The most superior point on the supraorbital margin \\
\hline Inferior orbitale & 10 & The most inferior point on the infraorbital margin \\
\hline Nasion & N & The most anterior point of the frontonasal suture \\
\hline Nasale & $\mathrm{Na}$ & The tip of the nasal bone \\
\hline Anterior nasal spine & Ans & The apex of the anterior nasal spine \\
\hline Mastoid tip & Mt & The most prominent point of the mastoid bone \\
\hline Porion & Po & The most superior margin of the external auditory meatus \\
\hline Zygomaticomaxillary suture & $\mathrm{Zm}$ & The most inferior point of the zygomaticomaxillary suture \\
\hline Zygotemporale & Zt & $\begin{array}{l}\text { The point with the greatest bony concavity between the frontal and } \\
\text { temporal processes of the zygoma }\end{array}$ \\
\hline Gnathion & Gn & The most inferior point of the mandible in the midline \\
\hline Gonion & Go & The most inferior, posterior, and lateral point on the mandibular angle \\
\hline Condylar process & $\mathrm{Cd}$ & The most prominent point of the condylar process \\
\hline Midsagittal plane & M & The plane passing through the basion and opisthion \\
\hline Coronal basion plane & C & $\begin{array}{l}\text { The plane perpendicular to the midsagittal plane and passing the basion } \\
\text { (the basion is the midpoint of the anterior border of the foramen magnum) }\end{array}$ \\
\hline Coronal opisthion plane & Co & $\begin{array}{l}\text { The plane perpendicular to the midsagittal plane and passing the opisthion } \\
\text { (the opisthion is the midpoint of the lower border of the foramen magnum) }\end{array}$ \\
\hline
\end{tabular}


scan was $14.4( \pm 5.1)$ months. The mean age of the two groups have apparent difference. But the aging process does not cause right or left sided skeletal asymmetry by itself. For the DP and control group infants, the mean value was determined for 24 variables. Pearson correlation coefficients matched with cranial vault asymmetry (CVA) were calculated. Quantitative differences in each variable are presented in Table 2 (relative difference) and Table 4 (correlation coefficient with CVA). The results of the comparison study with the control group are shown in Table 3.

With the exception of certain orbital asymmetry variables (frontozygomatic suture-porion [Fz-Po], frontomaxillary suturenasion [Fm-N], Fm-Fz, superior orbitale-inferior orbitale [So-Io]), facial asymmetry was greater in the DP group than in the control group. These findings were statistically significant (Table 3).

The degree of orbital asymmetry was not very large for children with DP (Table 2). There were poor associations between the orbital variables and CVA. The variable for orbitotragal depth (FzPo) was also not significantly related to plagiocephaly. However, the difference in orbital width $(\mathrm{Fz}-\mathrm{N})$ was associated with $\mathrm{CVA}$ (Table 4). The size of the orbital globe (Fm-Fz, So-Io) was not sig-

Table 2. RD in the percentage of each variable in the plagiocephaly group

\begin{tabular}{|c|c|c|c|c|}
\hline Facial asymmetry & $\operatorname{Min}(\%)$ & $\operatorname{Max}(\%)$ & Mean (\%) & $\mathrm{SD}$ \\
\hline \multicolumn{5}{|l|}{ Cranial vault asymmetry } \\
\hline Ft-Eu of opposite side & 3.8 & 19.8 & 11.0 & 4.0 \\
\hline \multicolumn{5}{|l|}{ Orbital asymmetry } \\
\hline $\mathrm{Fz}-\mathrm{Po}$ & -8.0 & 7.7 & -1.3 & 4.0 \\
\hline $\mathrm{Fz}-\mathrm{N}$ & -4.6 & 9.8 & 1.4 & 2.7 \\
\hline $\mathrm{Fm}-\mathrm{N}$ & -15.6 & 12.1 & 0.1 & 6.7 \\
\hline $\mathrm{Fm}-\mathrm{Fz}$ & -2.0 & 8.6 & 1.6 & 2.4 \\
\hline So-lo & -17.4 & 11.2 & 0.0 & 4.9 \\
\hline So-C & -2.7 & 10.4 & 3.4 & 2.9 \\
\hline $\mathrm{Fz}-\mathrm{C}$ & -6.4 & 21.0 & 4.1 & 5.5 \\
\hline \multicolumn{5}{|l|}{ Nasal asymmetry } \\
\hline $\mathrm{N}-\mathrm{Mt}$ & -10.2 & 2.5 & -4.3 & 2.6 \\
\hline Ans-Mt & -11.9 & 3.7 & -5.4 & 3.4 \\
\hline $\mathrm{Na}-\mathrm{M}^{\mathrm{a})}$ & -2.0 & 6.0 & 1.7 & 1.9 \\
\hline \multicolumn{5}{|l|}{ Auricular asymmetry } \\
\hline Mt-Po & -34.6 & 21.7 & -9.8 & 9.8 \\
\hline Po-Co & -2.7 & 42.0 & 7.1 & 7.0 \\
\hline \multicolumn{5}{|l|}{ Maxillar asymmetry } \\
\hline $\mathrm{Zm}-\mathrm{Mt}$ & -22.4 & 17.3 & -5.2 & 7.0 \\
\hline Zt-Mt & -14.6 & 10.6 & -3.4 & 6.1 \\
\hline lo-Zm & -10.1 & 18.8 & 5.2 & 7.0 \\
\hline $\mathrm{Zm}-\mathrm{C}$ & -6.1 & 13.6 & 2.6 & 4.5 \\
\hline \multicolumn{5}{|l|}{ Mandibular asymmetry } \\
\hline Gn-Go & -13.8 & 4.0 & -4.5 & 4.1 \\
\hline Go-Cd & -10.0 & 11.3 & 1.5 & 5.3 \\
\hline Gn-Mt & -11.6 & 8.2 & -4.0 & 4.0 \\
\hline $\mathrm{Gn}-\mathrm{Cd}$ & -9.7 & 5.1 & -3.7 & 3.0 \\
\hline Go-C & -8.1 & 66.7 & 16.8 & 17.0 \\
\hline $\mathrm{Cd}-\mathrm{C}$ & -10.5 & 63.8 & 17.2 & 15.5 \\
\hline $\mathrm{G}-\mathrm{C}^{\mathrm{a})}$ & -4.0 & 5.0 & 1.0 & 2.2 \\
\hline
\end{tabular}

$\mathrm{RD}$, relative difference; Min, minimal value; Max, maximal value; SD, standard deviation; Ft, frontal bossing; Eu, eurion; Fz, frontozygomatic suture; Po, porion; $\mathrm{N}$, nasion; Fm, frontomaxillary suture; So, superior orbitale; Io, inferior orbitale; C, coronal basion plane; Mt, mastoid tip; Ans, anterior nasal spine; Na, nasale; $\mathrm{M}$, midsagittal plane; $\mathrm{Co}$, coronal opisthion plane; $\mathrm{Zm}$, zygomaticomaxillary suture; $\mathrm{Zt}$, zygotemporale; $\mathrm{Gn}$, gnathion; Go, gonion; $\mathrm{Cd}$, condylar process.

a) Angular difference with the midsagittal plane, and the basion as a pivot point. 
nificantly different between the two groups. The measurement between the nasion and frontozygomatic suture $(\mathrm{Fz}-\mathrm{N})$ was the only orbital measurement that was significantly greater $(p=0.047)$ in the DP group than the control group (Table 3). However, this parameter was affected by both orbital and nasal asymmetry. In addition, the measurements from the coronal reference plane (So-coronal basion plane $[\mathrm{C}], \mathrm{Fz}-\mathrm{C}$ ) indicated significant asymmetry, and this result reflected the asymmetry of ipsilateral frontal bossing and deviation of the facial axis rather than bony deformity (Tables 2, 3).

Mandibular asymmetry and nasal deviation were common in the DP group. The analysis of mandibular and nasal asymmetry demonstrated apparent deviation (Table 2) highly correlated with the severity of CVA (Table 4). The distance variables (N-mastoid tip [Mt], anterior nasal spine [Ans]-Mt) and the angular differ- ence with the midsagittal plane (nasale $[\mathrm{Na}]$-midsagittal plane $[\mathrm{M}]$ ) of the nose showed significant deviation of the nose and mandible to the ipsilateral side (Tables 2, 3).

The ipsilateral mandibular body (gnathion [Gn]-gonion [Go]) usually was shorter than the contralateral side. Therefore, other measurements that included the mandibular body (Gn-Mt, Gncondylar process [Cd]) also showed such dicrepancy (Fig. 2). However, no such discrepancy was observed for the ramus (Go-Cd). Thus, mandibular asymmetry appears to reflect discrepancies in mandibular body length and mandibular deviation-the latter of which was apparent when analyzing variables measured from the reference planes (Go-C, Cd-C, Gn-C) (Table 2). The mandibular deformities highly correlated with the severity of CVA (Table 4). All of these mandibular asymmetries were significantly different from those of the control group (Table 3).

Table 3. Mean RD values (the absolute values) for the two groups

\begin{tabular}{|c|c|c|c|}
\hline Variable & $\begin{array}{l}\text { Plagiocephaly group } \\
(\mathrm{n}=48[61.5 \%])\end{array}$ & $\begin{array}{l}\text { Control group } \\
(n=30[38.5 \%])\end{array}$ & $p$-value \\
\hline Fz-Po & 3.5 & 3.0 & 0.380 \\
\hline $\mathrm{Fz}-\mathrm{N}$ & 2.2 & 1.4 & 0.047 \\
\hline $\mathrm{Fm}-\mathrm{N}$ & 5.3 & 6.6 & 0.518 \\
\hline $\mathrm{Fm}-\mathrm{Fz}$ & 2.0 & 2.0 & 0.904 \\
\hline So-lo & 3.6 & 2.6 & 0.089 \\
\hline So-C & 3.6 & 1.5 & $<0.001$ \\
\hline $\mathrm{Fz}-\mathrm{C}$ & 5.1 & 2.2 & $<0.001$ \\
\hline $\mathrm{N}-\mathrm{Mt}$ & 4.4 & 1.7 & $<0.001$ \\
\hline Ans-Mt & 5.6 & 1.9 & $<0.001$ \\
\hline $\mathrm{Na}-\mathrm{M}^{\mathrm{a})}$ & 1.9 & 0.2 & $<0.001$ \\
\hline Mt-Po & 11.4 & 5.8 & $<0.001$ \\
\hline Po-Co & 7.3 & 3.1 & $<0.001$ \\
\hline Zm-Mt & 7.4 & 2.9 & $<0.001$ \\
\hline Zt-Mt & 5.8 & 2.8 & $<0.001$ \\
\hline lo-Zm & 7.2 & 3.7 & 0.001 \\
\hline $\mathrm{Zm}-\mathrm{C}$ & 4.1 & 2.1 & 0.004 \\
\hline Gn-Go & 5.0 & 2.9 & 0.002 \\
\hline Go-Cd & 4.5 & 3.2 & 0.032 \\
\hline Gn-Mt & 4.6 & 1.5 & $<0.001$ \\
\hline $\mathrm{Gn}-\mathrm{Cd}$ & 4.0 & 1.5 & $<0.001$ \\
\hline Go-C & 17.8 & 9.0 & $<0.001$ \\
\hline $\mathrm{Cd}-\mathrm{C}$ & 18.2 & 9.0 & $<0.001$ \\
\hline $\mathrm{Gn}-\mathrm{C}^{\mathrm{a})}$ & 1.8 & 0.6 & $<0.001$ \\
\hline
\end{tabular}

$\mathrm{RD}$, relative difference; Fz, frontozygomatic suture; Po, porion; N, nasion; Fm, frontomaxillary suture; So, superior orbitale; Io, inferior orbitale; C, coronal basion plane; Mt, mastoid tip; Ans, anterior nasal spine; Na, nasale; M, midsagittal plane; Co, coronal opisthion plane; Zm, zygomaticomaxillary suture; Zt, zygotemporale; $\mathrm{Gn}$, gnathion; Go, gonion; $\mathrm{Cd}$, condylar process.

a) The $p$-values for continuous variables were obtained with Student $t$-tests. 

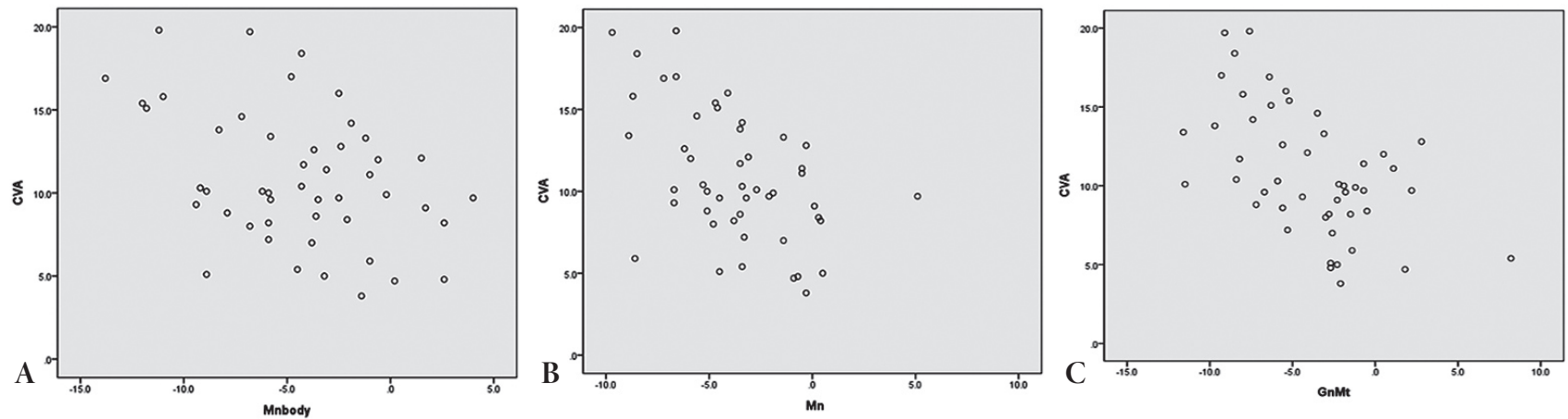

Fig. 2. Correlation between mandibular deformity and CVA for each patient. (A) Mandibular body (Gn-Go), (B) whole mandible (Gn-Cd), (C) mandible to mastoid (Gn-Mt). CVA, cranial vault asymmetry; $\mathrm{Gn}$, gnathion; $\mathrm{Go}$, gonion; $\mathrm{Cd}$, condylar process; Mt, mastoid tip.

Auricular asymmetry (Mt-Po, Po-Co) did not significantly correlate with severity of CVA (Table 3), but the presence of asymmetry was confirmed by the high mean RD value (Table 2).

The maxilla showed little asymmetry. There was a trend toward an irregular RD value (Table 2), but no significant correlation with CVA severity was found (Table 4).

\section{DISCUSSION}

The term plagiocephaly is derived from the Greek words plagio (oblique) and kephale (head). Deformation plagiocephaly refers to such morphological changes acquired after birth. The asymmetry in patients with plagiocephaly is not limited to head shape. Recently, few studies have reported consistent facial changes in patients with DP, including zygomatic asymmetry, jaw deformity, and occlusion function. Some authors have reported orbital, auditory, and even neurodevelopmental sequelae [9]. However, these functional consequences are not common and are still under debate $[9,10]$.

Facial asymmetry in DP results from facial bone changes following subsequent skull base deformation. In order to review the literature regarding facial asymmetry and CVA, PubMed was used to search for the following terms: "deformational plagiocephaly," "positional plagiocephaly," "facial asymmetry," "facial analysis," "three dimensional facial analysis." The search inquiry identified studies mentioned above [10,11]. However, none of the studies had investigated the severity of head deformity with respect to facial skeletal asymmetry.
Table 4. CC between CVA and each variable in the plagiocephaly group

\begin{tabular}{|c|c|c|}
\hline Variable & $\mathrm{CC}$ & $p$-value \\
\hline \multicolumn{3}{|c|}{ Orbital asymmetry } \\
\hline $\mathrm{Fz}-\mathrm{Po}$ & -0.229 & 0.117 \\
\hline $\mathrm{Fz}-\mathrm{N}$ & 0.348 & 0.016 \\
\hline $\mathrm{Fm}-\mathrm{N}$ & 0.169 & 0.251 \\
\hline $\mathrm{Fm}-\mathrm{Fz}$ & 0.341 & 0.018 \\
\hline So-lo & -0.168 & 0.255 \\
\hline So-C & 0.299 & 0.039 \\
\hline $\mathrm{Fz}-\mathrm{C}$ & 0.301 & 0.038 \\
\hline \multicolumn{3}{|c|}{ Nasal asymmetry } \\
\hline $\mathrm{N}-\mathrm{Mt}$ & -0.412 & 0.004 \\
\hline Ans-Mt & -0.503 & $<0.001$ \\
\hline $\mathrm{Na}-\mathrm{M}^{2 a}$ & 0.543 & $<0.001$ \\
\hline \multicolumn{3}{|c|}{ Auricular asymmetry } \\
\hline Mt-Po & -0.022 & 0.883 \\
\hline Po-Co & 0.171 & 0.244 \\
\hline \multicolumn{3}{|c|}{ Maxillary asymmetry } \\
\hline Zm-Mt & -0.061 & 0.678 \\
\hline Zt-Mt & -0.024 & 0.871 \\
\hline lo-Zm & 0.102 & 0.489 \\
\hline $\mathrm{Zm}-\mathrm{C}$ & 0.087 & 0.557 \\
\hline \multicolumn{3}{|c|}{ Mandibular asymmetry } \\
\hline Gn-Go & -0.413 & 0.004 \\
\hline Go-Cd & -0.022 & 0.883 \\
\hline Gn-Mt & -0.539 & $<0.001$ \\
\hline $\mathrm{Gn}-\mathrm{Cd}$ & -0.513 & $<0.001$ \\
\hline Go-C & 0.014 & 0.343 \\
\hline $\mathrm{Cd}-\mathrm{C}$ & 0.061 & 0.680 \\
\hline $\mathrm{Gn}-\mathrm{C}^{\mathrm{a})}$ & 0.284 & 0.051 \\
\hline
\end{tabular}

CC, correlation coefficients; CVA, cranial vault asymmetry; Fz, frontozygomatic suture; Po, porion; N, nasion; Fm, frontomaxillary suture; So, superior orbitale; Io, inferior orbitale; $\mathrm{C}$, coronal basion plane; $\mathrm{Mt}$, mastoid tip; Ans, anterior nasal spine; $\mathrm{Na}$, nasale; $\mathrm{M}$, midsagittal plane; $\mathrm{Co}$, coronal opisthion plane; Zm, zygomaticomaxillary suture; Zt, zygotemporale; Gn, gnathion; $\mathrm{Go}$, gonion; $\mathrm{Cd}$, condylar process.

a) Angular differences with the midsagittal plane, and the basion as a pivot point. 
Since DP is not an all-or-nothing phenomenon, we had to determine diagnostic criteria before beginning this study, which have not been clearly established in literature. Anthropomorphic measurements of CVA [12,13], diagonal differences [14], or transcranial differences [15] have been proposed as diagnostic parameters. However, no single measurement appears superior at present time. Furthermore, published diagnostic tools were based on surface anthropometric measurements, not measurements of the skeletal structure itself. For these reasons, we felt the need to develop a new criterion in this study and decided a $5 \mathrm{~mm}$ difference in diagonal distance on 3D reconstructed CT scan.

Concerning skeletal landmarks, other authors have stressed that the symmetry of mastoid bone is conserved in typical DP anthropometry [16]. However, we were unable to find such symmetry in our patients and could not use the mastoid bone a reliable reference point. Instead, we adopted reference planes, which are minimally affected by the deformational force on the skull structure. In contrast to synostotic plagiocephaly, DP rarely causes deviation in the midline structures of the skull base with the basion and the opisthion being in the same axis $[7,8]$. Thus, we used the midsagittal plane and two coronal planes as reference for the evaluation of facial asymmetry.

In contrast to our expectation, we found that the degree of orbital and maxillary asymmetry was not very large in children with DP. The anterior displacement of these structures appeared to move in concert with the adjacent skull structures without bony shortening. In this context, the orbitotragal depth (Fz-Po) did not show a significant difference between bilateral sides (Table $2)$, in contrast to results of previous studies $[10,11]$. The variables for maxilla revealed irregular RD values, which indicated that the maxilla was less affected by deformational force.

However, the coronal reference planes through the basion and the opisthion were clearly demonstrated landmarks associated with facial asymmetry. This trend was also found in orbital variables. These results indicate that facial asymmetry is caused by overall skeletal distortion rather than shortening of specific bones.

St John et al. [17] have reported on mandibular changes in DP. They suggested that mandibular asymmetry in DP was secondary to cranial base deformity and anterior movement of temporo- mandibular joint but not the consequence of mandibular bony deformities. However, we observed shortening of the mandibular bone in patients with DP in this study. The deformity of the mandible was limited to the body rather than the ramus, and the ipsilateral deviation of the gnathion can be attributed to this discrepancy in the length of mandibular body.

To conclude, infants with plagiocephaly had significantly asymmetry in the mandible and nasal structures. Mandibular values were found to have significant asymmetry in the DP group, while those of the control group were relatively symmetric. Orbital asymmetry was found only when the new reference planes were used. There was little deformity in the maxilla. These results suggest that the facial bone is distorted and the axis is deviated by the deformational force in children with DP. However, the exact mechanism behind this remains unclear. Future work will focus on uncovering this mechanism and the effect of cranial orthotic helmet therapy on the facial asymmetry.

DP is the most common head deformity in infants. Our anthropometric analysis demonstrated that the deformational force contribute not only to both cranial vault deformity but also to facial asymmetry. More specifically, children with DP tended to have greater asymmetry of the nose and mandible. Facial asymmetry in plagiocephaly is caused by an overall skeletal distorting force that changes the facial axis. Future studies are needed to understand the exact mechanism of these findings and to evaluate the progressive effect of different treatment modalities has on both cranial vault and facial skeletons.

\section{REFERENCES}

1. Persing J, James H, Swanson J, Kattwinkel J; American Academy of Pediatrics Committee on Practice and Ambulatory Medicine, Section on Plastic Surgery and Section on Neurological Surgery. Prevention and management of positional skull deformities in infants. American Academy of Pediatrics Committee on Practice and Ambulatory Medicine, Section on Plastic Surgery and Section on Neurological Surgery. Pediatrics 2003;112:199-202.

2. Kane AA, Mitchell LE, Craven KP, Marsh JL. Observations on a recent increase in plagiocephaly without synostosis. Pediatrics 1996;97: 877-85.

3. Mathews TJ, Menacker F, MacDorman MF. Infant mortality statistics from the 2001 period linked birth/infant death data set. Natl Vital Stat 
Rep 2003;52:1-28.

4. Konig M, Vanscheidt W, Augustin M, Kapp H. Enzymatic versus autolytic debridement of chronic leg ulcers: a prospective randomised trial. J Wound Care 2005;14:320-3.

5. Nellhaus G. Head circumference from birth to eighteen years. Practical composite international and interracial graphs. Pediatrics 1968;41:106-14.

6. Niklasson A, Albertsson-Wikland K. Continuous growth reference from 24th week of gestation to 24 months by gender. BMC Pediatr 2008;8:8.

7. Captier G, Leboucq N, Bigorre M, Canovas F, Bonnel F, Bonnafe A, Montoya P. Plagiocephaly: morphometry of skull base asymmetry. Surg Radiol Anat 2003;25:226-33.

8. Lo LJ, Marsh JL, Pilgram TK, Vannier MW. Plagiocephaly: differential diagnosis based on endocranial morphology. Plast Reconstr Surg 1996;97:282-91.

9. Robinson S, Proctor M. Diagnosis and management of deformational plagiocephaly. J Neurosurg Pediatr 2009;3:284-95.

10. Kelly KM, Littlefield TR, Pomatto JK, Ripley CE, Beals SP, Joganic EF. Importance of early recognition and treatment of deformational plagiocephaly with orthotic cranioplasty. Cleft Palate Craniofac J 1999;36:127-30.
11. Teichgraeber JF, Ault JK, Baumgartner J, Waller A, Messersmith M, Gateno J, Bravenec B, Xia J. Deformational posterior plagiocephaly: diagnosis and treatment. Cleft Palate Craniofac J 2002;39:582-6.

12. Littlefield TR, Beals SP, Manwaring KH, Pomatto JK, Joganic EF, Golden KA, Ripley CE. Treatment of craniofacial asymmetry with dynamic orthotic cranioplasty. J Craniofac Surg 1998;9:11-7.

13. Mortenson PA, Steinbok P. Quantifying positional plagiocephaly: reliability and validity of anthropometric measurements. J Craniofac Surg 2006;17:413-9.

14. Graham JM Jr, Gomez M, Halberg A, Earl DL, Kreutzman JT, Cui J, Guo X. Management of deformational plagiocephaly: repositioning versus orthotic therapy. J Pediatr 2005;146:258-62.

15. Rogers GF, Miller J, Mulliken JB. Comparison of a modifiable cranial cup versus repositioning and cervical stretching for the early correction of deformational posterior plagiocephaly. Plast Reconstr Surg 2008;121:941-7.

16. Losee JE, Mason AC. Deformational plagiocephaly: diagnosis, prevention, and treatment. Clin Plast Surg 2005;32:53-64.

17. St John D, Mulliken JB, Kaban LB, Padwa BL. Anthropometric analysis of mandibular asymmetry in infants with deformational posterior plagiocephaly. J Oral Maxillofac Surg 2002;60:873-7. 